\title{
Review Article \\ D-Amino Acids in the Nervous and Endocrine Systems
}

\author{
Yoshimitsu Kiriyama and Hiromi Nochi \\ Kagawa School of Pharmaceutical Sciences, Tokushima Bunri University, Shido 1314-1, Sanuki, Kagawa 769-2193, Japan
}

Correspondence should be addressed to Hiromi Nochi; nochi@kph.bunri-u.ac.jp

Received 13 September 2016; Accepted 14 November 2016

Academic Editor: Mirko Diksic

Copyright (C) 2016 Y. Kiriyama and H. Nochi. This is an open access article distributed under the Creative Commons Attribution License, which permits unrestricted use, distribution, and reproduction in any medium, provided the original work is properly cited.

\begin{abstract}
Amino acids are important components for peptides and proteins and act as signal transmitters. Only L-amino acids have been considered necessary in mammals, including humans. However, diverse $\mathrm{D}$-amino acids, such as $\mathrm{D}$-serine, $\mathrm{D}$-aspartate, $\mathrm{D}$-alanine, and $\mathrm{D}$-cysteine, are found in mammals. Physiological roles of these $\mathrm{D}$-amino acids not only in the nervous system but also in the endocrine system are being gradually revealed. N-Methyl-D-aspartate (NMDA) receptors are associated with learning and memory. D-Serine, $\mathrm{D}$-aspartate, and D-alanine can all bind to NMDA receptors. $\mathrm{H}_{2} \mathrm{~S}$ generated from $\mathrm{D}$-cysteine reduces disulfide bonds in receptors and potentiates their activity. Aberrant receptor activity is related to diseases of the central nervous system (CNS), such as Alzheimer's disease, amyotrophic lateral sclerosis, and schizophrenia. Furthermore, D-amino acids are detected in parts of the endocrine system, such as the pineal gland, hypothalamus, pituitary gland, pancreas, adrenal gland, and testis. D-Aspartate is being investigated for the regulation of hormone release from various endocrine organs. Here we focused on recent findings regarding the synthesis and physiological functions of $\mathrm{D}$-amino acids in the nervous and endocrine systems.
\end{abstract}

\section{Introduction}

Amino acids are important not only as essential components for the building blocks of peptides and proteins but also as biochemical regulators, such as neurotransmitters [1-4] and autophagy regulators [5-8]. D-Amino acids are enantiomers of $\mathrm{L}$-amino acids and have been considered to be absent and unnatural amino acids in mammals for a long time. However, the recent development of sensitive analytical methods elucidated the presence of $\mathrm{D}$-amino acids, such as $\mathrm{D}$-serine, $\mathrm{D}$ aspartate, and D-alanine, in mammals [9-11]. Moreover, studies on the enzymes that synthesize or metabolize D-amino acids have also clarified the localization and functions of $\mathrm{D}$ amino acids in the nervous and endocrine systems and found that $\mathrm{D}$-amino acid synthesis and metabolism are physiologically regulated [12-15]. Here we focused on recent advances in understanding the synthesis, metabolism, and physiological roles of D-amino acids in the nervous and endocrine systems.

\section{D-Serine}

Marked levels of D-serine were found in the central nervous system (CNS) of rodents and humans. D-Serine-abundant regions in the CNS were the cerebral cortex, hippocampus, and striatum. Additionally, D-serine is also detectable in other regions, such as the midbrain, cerebellum, and spinal cord, of rodents and humans [16-19]. The extracellular levels of D-serine in the medial prefrontal cortex and striatum of rats are approximately $20 \%$ of the total level of serine [20]. DSerine is biosynthesized by serine racemase (SR) in the CNS of rodents and humans [21-23]. In addition, the level of Dserine in the CNS is considerably decreased in $\mathrm{Sr}$ knockout mice $[24,25]$.

It was shown that SR localizes to astrocytes as well as neurons and D-serine was released from both [22, 23, 26-29]. In addition, $\mathrm{D}$-serine in the neurons is generated from $\mathrm{L}$-serine provided from astrocytes [27]. The D-serine shuttle model describes optimal D-serine-mediated N-methyl-D-aspartate (NMDA) receptor activity by proposing that $\mathrm{D}$-serine is transported between neurons and astrocytes [30, 31]. This Dserine shuttle model is as follows. Astrocytes uptake glucose from the blood vessels via glucose transporter 1 and then 3phosphoglycerate dehydrogenase (Phgdh), which is mainly localized in astrocytes and converts glucose to L-serine. LSerine is exported from astrocytes and imported into neurons through alanine/serine/cysteine/threonine transporters 
(ASCTs). In the neuron, L-serine is converted to D-serine by SR. D-serine is released from neurons, through alanineserine-cysteine transporter-1 (Asc-1) or other pathways, into the synapse where it can regulate NMDA receptor activity. Released D-serine can also be imported into astrocytes through ASCTs. The ability of SR to racemize L-serine to $\mathrm{D}$-serine is positively regulated by pyridoxal- $5^{\prime}$-phosphate (PLP), divalent cations, and ATP [22, 32, 33]. On the other hand, the activity of SR is inhibited by its translocation from the cytosol to membranes that contain phosphatidylinositol 4,5-bisphosphate $\left(\mathrm{PIP}_{2}\right)$, such as the nuclear, endoplasmic reticulum (ER), and plasma membranes [34-37]. SR is also regulated by interaction with other proteins (Figure 1). Glutamate receptor interacting protein 1 (GRIP1) [38] and protein interacting with C-kinase (PICK1) $[39,40]$ have been found to activate SR by interacting with it in the astrocytes of rodents. GRIP1 binds to the $\alpha$-amino-3-hydroxy-5methylisoxazole-4-propionic acid (AMPA) receptor and is released following stimulation with L-glutamate. The released GRIP1 binds and activates SR [38]. The postsynaptic density protein 95 (PSD95)/Discs large/ZO-1 (PDZ) domain in the Cterminal region of GRIP1 was found to be responsible for the interaction with SR $[38,41]$. PICK1 has a PDZ domain that binds to SR [39] and a Bin/amphiphysin/Rvs (BAR) domain that interacts with membranes [42]. PICK1 associates with erythropoietin-producing hepatocellular receptor (Eph)B3 or EphA4 in astrocytes. After ephrinB3 that is expressed on postsynaptic neurons binds to the EphB3 or EphA4 receptor, PICK1 is released into the cytosol. Enhancement of the association between the released PICK1 and SR increases the synthesis of D-serine in the astrocytes of mice [40]. Stargazin and F-box only protein $22(\mathrm{FBXO} 22)$ also regulate SR activity by affecting subcellular localization of SR. Stargazin forms a complex with the resting AMPA receptor, PSD-95, and SR, inhibiting the activity of SR by promoting membrane localization in the neurons of mice. Once the AMPA receptor is activated, SR is released from stargazin and the plasma membrane, leading to the activation of SR [43]. FBXO22 binds and activates SR by preventing its binding to the ER membrane in the neurons and astrocytes of rats. FBXO22 may block the lipid-binding region of SR [35].

D-Serine is catalyzed by SR and D-amino acid oxidase (DAO). SR has $\alpha, \beta$-elimination and racemization activities. SR converts both $\mathrm{D}$-serine and L-serine to generate pyruvate and ammonia by removing water from these amino acids by $\alpha, \beta$-elimination [44]. Therefore, SR might regulate the physiological level of $\mathrm{D}$-serine by racemization activity to synthesize $\mathrm{D}$-serine and by $\alpha, \beta$-elimination activity to degrade $\mathrm{D}$-serine. $\mathrm{DAO}$ is the flavoprotein that converts $\mathrm{D}$-serine to produce the corresponding alpha keto acid, hydrogen peroxide, and ammonia [11].

The distribution of D-serine in the CNS was found to be similar to that of NMDA receptors, which are ionotropic glutamate receptors (iGluRs) [18, 45], and the activation of NMDA receptors requires the binding of both glutamate and $\mathrm{D}$-serine or glycine. The activated NMDA receptors induce
$\mathrm{Ca}^{2+}$ flow, leading to the regulation of long-term potentiation (LTP) and long-term depression (LTD) in different areas of the CNS. Thus, the regulation of NMDA receptors is highly associated with synaptic activities, learning, and memory [46-49].

The NMDA receptor is mainly composed of two GluN1 subunits and two GluN2 subunits of either same or different GluN2 subunits. Glutamate binds to GluN2, whereas Dserine or glycine binds to GluN1 [50-52]. Although D-serine or glycine can act as the coagonist for NMDA receptors [46], reduction in the level of $\mathrm{D}$-serine diminishes the NMDA receptor activity and addition of D-serine reverses this inactivation, leading to LTP $[46,53]$. Moreover, D-serine induces LTP, and the degradation of D-serine by DAO leads to the suppression of this induction [49]. Therefore, D-serine plays important roles in the regulation of synaptic activities, learning, and memory by regulating the activation of NMDA receptors. However, neurotoxic effects of D-serine have been reported. Compared with wild-type mice, reduced levels of D-serine in adult $S r$ knockout mice diminished NMDA receptor-mediated and $\beta$-amyloid - $_{1-42}$-induced neurotoxicity [24]. Moreover, elevated levels of D-serine in adult Dao knockout mice resulted in motor neuron degeneration [54]. Aberrant levels of D-serine are associated with diseases caused by abnormal NMDA receptor activity. Levels of Dserine in the cerebrospinal fluid (CSF) of patients with Alzheimer's disease were reported to be higher than those reported in normal controls $[55,56]$. In addition, betaamyloid-induced neurotoxicity is suppressed in $\mathrm{Sr}$ knockout mice, which showed a $90 \%$ decrease in the level of D-serine in the brain [24]. Schizophrenia is associated with hypofunction of NMDA receptors [57]. Decreased D-serine level resulted in hypofunction of NMDA receptors and this leads to schizophrenia-like symptoms [25, 58]. Moreover, administration of D-serine ameliorates positive, negative, and cognitive symptoms in patients with schizophrenia [59]. Amyotrophic lateral sclerosis (ALS) is related with increased levels of Dserine $[60,61]$. Therefore, controlling the level of D-serine might be one of therapeutic targets for these diseases.

On the other hand, $\mathrm{D}$-serine binds to the $\delta 2$-type glutamate receptor (GluD2), which is iGluR, and drives the reduction of AMPA receptors in Purkinje cells in the cerebellum by endocytosis. This results in the promotion of cerebellar LTD. Moreover, binding of D-serine to GluD2 leads to the acquisition of motor learning in mice [62]. Recently, it has been reported that the age-dependent increase in pyruvate carboxylase activity in glial cells causes a decrease in the level of $\mathrm{D}$-serine, leading to age-related memory impairment in flies [63]. Pyruvate carboxylase generates oxaloacetic acid, which can be converted to aspartic acid. Both oxaloacetic acid and aspartic acid can inhibit SR, resulting in a decrease in the levels of D-serine [64].

D-Serine has also been found in endocrine organs, such as the adrenal and pituitary glands, pancreas, and testis, of rats $[65,66]$. However, levels of D-serine in the endocrine system are much lower than those in the CNS, and the physiological role of $\mathrm{D}$-serine in the endocrine systems remains unclear. 


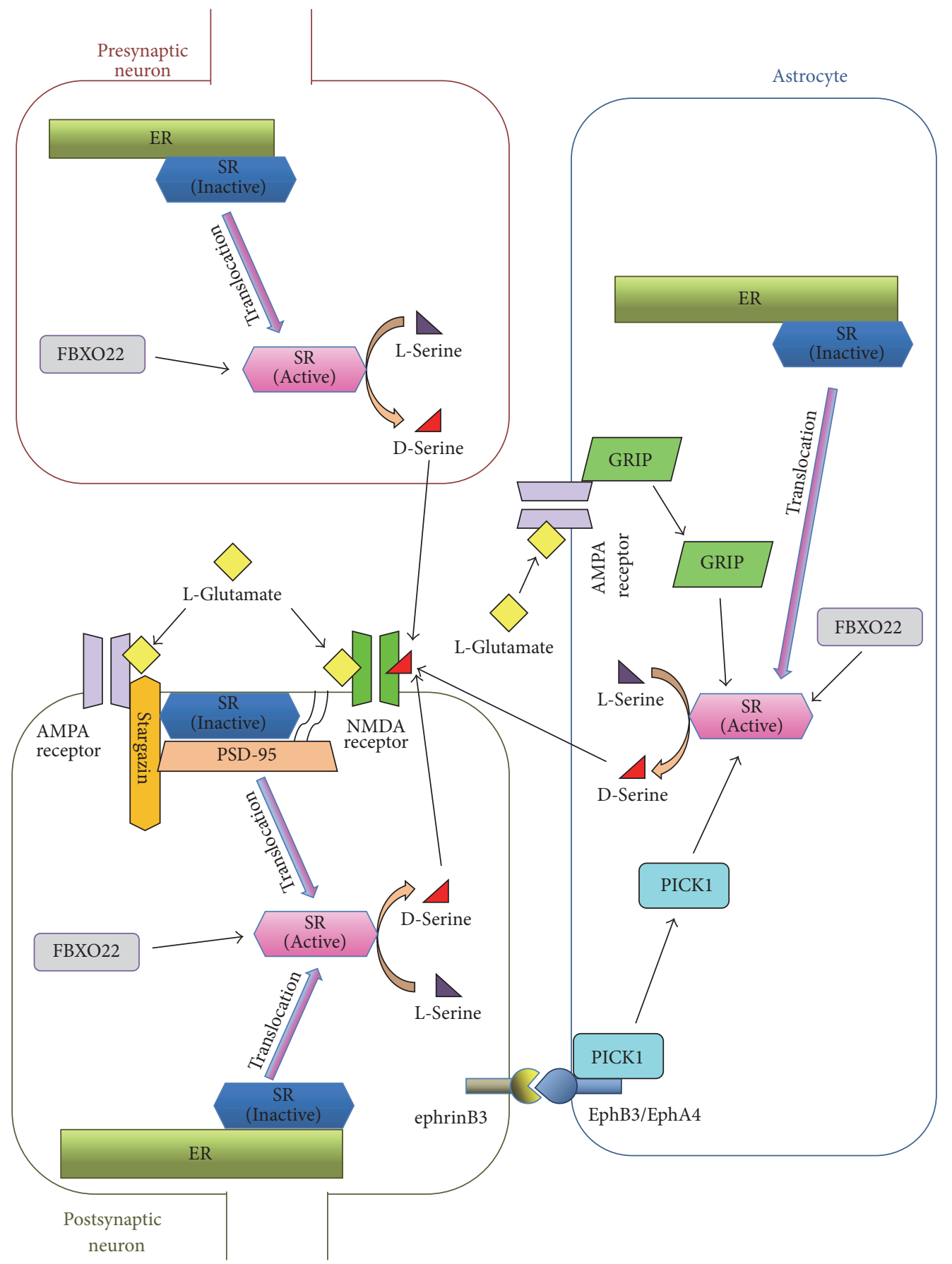

FIGURE 1: The synthesis of D-serine in the central nervous systems (CNS). D-Serine is synthesized by serine racemase (SR). SR is inhibited by its translocation from the cytosol to a membrane, such as the endoplasmic reticulum (ER) or plasma membranes, all of which contain phosphatidylinositol 4,5-bisphosphate $\left(\mathrm{PIP}_{2}\right)$. F-box only protein 22 (FBXO22) interacts with SR and activates SR by preventing it from binding to the ER membrane. In astrocytes, glutamate receptor interacting protein 1 (GRIP1) binds to the $\alpha$-amino-3-hydroxy-5methylisoxazole-4-propionic acid (AMPA) receptor and GRIP1 is then released from the AMPA receptor following stimulation with Lglutamate. Released GRIP1 activates SR. Protein interacting with C-kinase (PICK1) binds to erythropoietin-producing hepatocellular receptor (Eph)B3 or EphA4 in the astrocytes. PICK1 is released after ephrinB3 on the neurons interacts with the EphB3 or EphA4 receptor and then activates SR. Stargazin forms a complex with the AMPA receptor, postsynaptic density protein 95 (PSD-95), and SR and inhibits the activity of SR by promoting membrane localization in neurons. After the AMPA receptor is activated, SR is released from the plasma membrane, resulting in the activation of SR. The N-methyl-D-aspartate (NMDA) receptor is activated by glutamate and $\mathrm{D}$-serine. 


\section{D-Aspartate}

D-Aspartate is found in the CNS of rodents and humans [16, $19,67-72]$ as well as in endocrine organs, including the pineal gland $[69,72,73]$, pituitary gland $[68,69,71,72,74]$, pancreas [66], adrenal gland $[19,67,72,74,75]$, and testis, of rats $[74,76]$. D-Aspartate activates NMDA receptors via binding to the agonist site of GluN2 subunits (2A-D) [77-79] and can also activate metabotropic glutamate receptor 5 (mGlu5) [80]. Although the enzyme that generates $\mathrm{D}$-aspartate has not been identified yet [81-83], the generation of D-aspartate might be dependent on PLP [67].

On the other hand, it has been demonstrated that Daspartate is degraded to oxaloacetate, hydrogen peroxide, and ammonium by the peroxisomal flavoprotein $\mathrm{D}$-aspartate oxidase (DDO) [84-86]. Although D-aspartate is abundant in the brains of rodents and humans during development, levels of D-aspartate are extremely decreased at postnatal stages and this reduction remains throughout adulthood $[16,67,68,71$, 87,88 ]. In contrast, DDO activity and its mRNA are exceedingly low at postnatal stages and increase after birth in rodents $[88,89]$. Moreover, it has been shown that D-aspartate levels were significantly elevated in the CNS of Ddo knockout mice $[88,90-93]$. In addition, D-aspartate is found exclusively in the neurons of rats [67]. Improvement in spatial memory was demonstrated in Ddo knockout mice $[77,78]$. Moreover, Daspartate-treated mice and $D d o$ knockout mice demonstrated an enhancement of LTP [77-79] and increase in the dendritic length and spine density in neurons in the prefrontal cortex and hippocampus [94]. Therefore, a significant increase in levels of D-aspartate, enhancement of LTP, and increase in the dendritic length and spine density of neurons in adult $D d o$ knockout mice indicate that D-aspartate might also be generated and function in CNS during adulthood. However, persistent elevation in levels of D-aspartate in adult Ddo knockout mice has neurotoxic effects, such as activation of caspase-3 and apoptosis in neurons [88]. The expression of Ddo mRNA in postmortem brains of patients with schizophrenia was significantly higher than that in control individuals [95]. Moreover, it has been reported that the levels of D-aspartate were significantly reduced in the postmortem brains of patients with schizophrenia compared with those in control individuals [96]. Ddo knockout mice exhibit reduced schizophrenialike behaviors induced by phencyclidine, such as motor hyperactivity and prepulse inhibition [95]. These findings indicate that an aberrant level of D-aspartate may be associated with schizophrenia.

In the endocrine system, D-aspartate controls the synthesis and release of hormones. D-Aspartate inhibits the synthesis of melatonin in the rat pineal gland [97] and also reduces the release of melatonin from cultured rat pinealocytes [98]. In the rat hypothalamus, D-aspartate induces oxytocin and vasopressin gene expression [99] and may increase the release of gonadotropin-releasing hormone [100]. D-Aspartate also induces the release of prolactin [101], growth hormone, and luteinizing hormone $[100,102]$ from the rat anterior pituitary. In contrast, an increase in the levels of $\mathrm{D}$-aspartate is associated with considerable decrease in proopiomelanocortin and $\alpha$-melanocyte-stimulating hormone in the mouse intermediate lobe [93]. In the rat testis, D-aspartate induces the synthesis and release of testosterone [102-104]. Upregulated androgen and downregulated estrogen receptor expressions by D-aspartate administration were shown in rat testis [104]. Moreover, the oral intake of $\mathrm{D}$-aspartate induces the release of testosterone in human serum [102] and ameliorates the number and motility of the spermatozoa in humans [105]. Therefore, it is expected that D-aspartate could be a candidate for infertility treatment.

\section{Other D-Amino Acids}

Various D-amino acids other than D-serine and D-aspartate were also found in the nervous and endocrine systems.

D-Alanine is detected in the brain, pituitary gland, pancreas, adrenal gland, and testis of rodents [106]. In addition, it is also detected in the human brain [107]. Most of the Dalanine in rodents is derived from intestinal bacteria [108, 109]. D-Alanine is metabolized by DAO [11], and the levels of $\mathrm{D}$-alanine in rodents depend on the circadian rhythm $[9,110]$. In addition, it has been reported that $\mathrm{D}$-alanine binds to the NMDA receptor and improves the symptoms of patients with schizophrenia [111].

D-Cysteine was found to be one of sources of $\mathrm{H}_{2} \mathrm{~S}$ in the brain (Figure 2). D-Cysteine is probably absorbed at least partially from food, although the source of D-cysteine in the body has not been elucidated thus far [112]. In the CNS, Dcysteine is degraded by DAO to generate 3-mercaptopyruvate (3MP). $3 \mathrm{MP}$ is then catalyzed by 3-mercaptopyruvate sulfurtransferase (3MST) to produce $\mathrm{H}_{2} \mathrm{~S}$ [113]. 3MST is found in the synaptosomes and neurons of mouse brains [114]. Moreover, hydrogen polysulfides $\left(\mathrm{H}_{2} \mathrm{~S}_{n} ; n=2-5\right)$ are found in the mouse brain and are also generated by 3MST from $3 \mathrm{MP}$ [115]. $\mathrm{H}_{2} \mathrm{~S}$ enhances the activity of NMDA receptors by reducing disulfide bonds in NMDA receptors and induces LTP in rats $[116,117]$. In contrast, $\mathrm{H}_{2} \mathrm{~S}_{n}$ activates the transient receptor potential (TRP) A1 channels in rodent astrocytes and induces the flow of $\mathrm{Ca}^{2+}$ [118]. Activation of TRPA1 channels leads to D-serine release from rodent astrocytes and enhances NMDA receptor-dependent LTP [119]. In addition, Parkin is one of the key factors for Parkinson's disease [7], and $\mathrm{H}_{2} \mathrm{~S}$ enhances the activity of Parkin and leads to protective effects against Parkinson's disease [120]. In the endocrine system, $\mathrm{H}_{2} \mathrm{~S}$ inhibits glucose-induced insulin release from pancreatic $\beta$ cells [121].

D-leucine and D-proline are found in the brain and pineal and pituitary gland of rodents $[122,123]$. D-glutamate is found in the rodent brain [70, 124]. However, detailed physiological roles of these amino acids remain unclear.

\section{Conclusions}

It has been considered that only L-amino acids are utilized in mammals, including humans. However, because of the recent development of sensitive and selective analytical methods for detecting chiral amino acids [125], diverse D-amino acids have been found in mammalian tissues. The physiological 


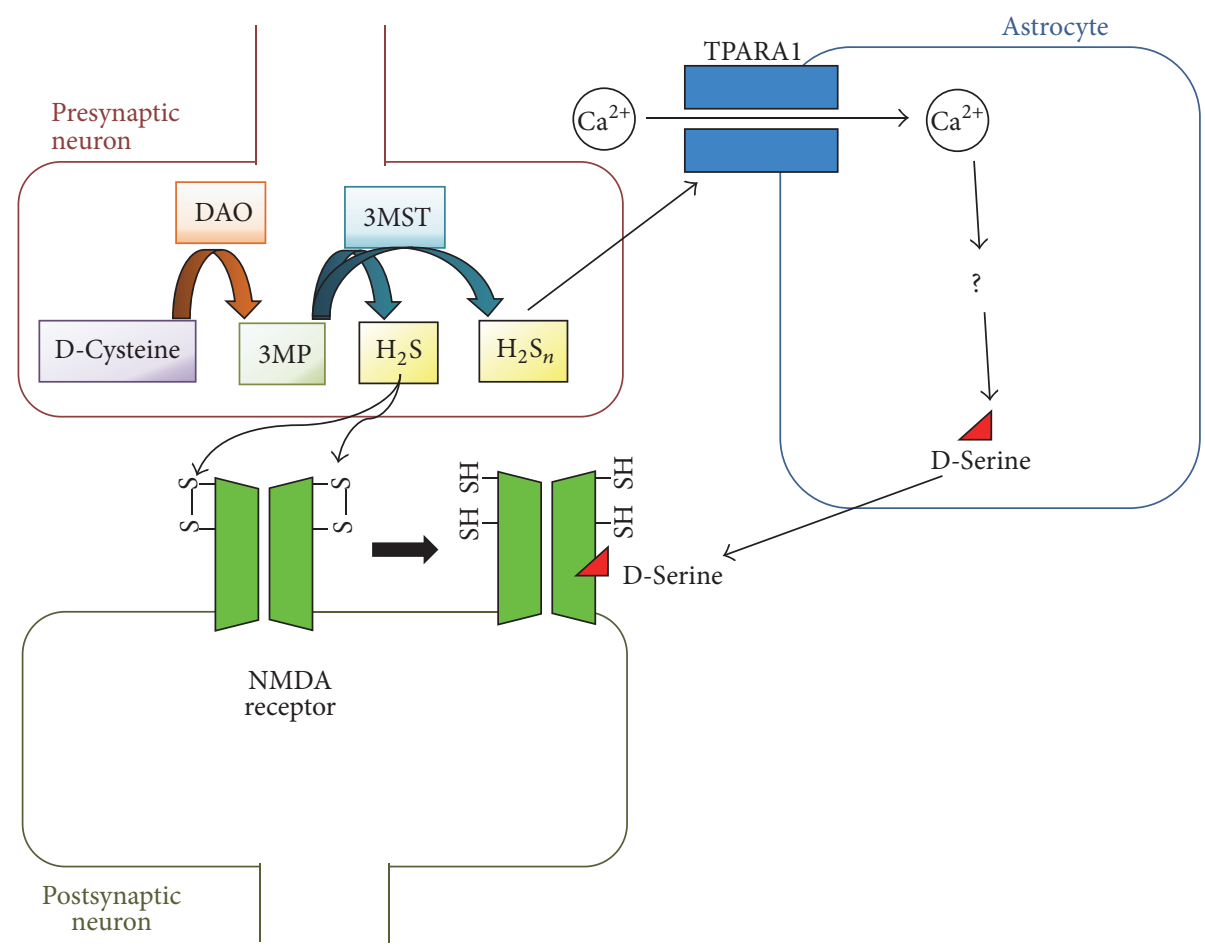

Figure 2: Activation of the N-methyl-D-aspartate (NMDA) receptor by D-cysteine. D-Cysteine is one of the sources of $\mathrm{H}_{2} \mathrm{~S}$ in the brain. $\mathrm{D}$-Cysteine is converted to 3 -mercaptopyruvate (3MP) by D-amino acid oxidase (DAO). 3MP is then degraded by 3 -mercaptopyruvate sulfurtransferase (3MST) to generate $\mathrm{H}_{2} \mathrm{~S}$ in the neurons. Hydrogen polysulfides $\left(\mathrm{H}_{2} \mathrm{~S}_{n} ; n=2-5\right)$ are also generated by $3 \mathrm{MST}$ from $3 \mathrm{MP}$. $\mathrm{H}_{2} \mathrm{~S}$ reduces the disulfide bonds in the NMDA receptor and increases the activity of the NMDA receptor. $\mathrm{H}_{2} \mathrm{~S}_{n}$ also activates the transient receptor potential (TRP) A1 channel. Activated TRPA1 channel induces $\mathrm{Ca}^{2+}$ influx, leading to D-serine release in astrocytes, and D-serine then activates the NMDA receptor.

functions of these D-amino acids are being gradually clarified. It has been demonstrated that D-amino acids, such as Dserine, D-aspartate, D-alanine, and D-cysteine, play important roles in the nervous and endocrine systems. Therefore, it is very important that the mechanisms of synthesis and metabolism as well as the physiological functions of D-amino acids are investigated further. These investigations will provide new therapeutic and diagnostic strategies for diseases related to the nervous and endocrine systems.

\section{Competing Interests}

The authors declare that they have no competing interests.

\section{References}

[1] J. W. McDonald and M. V. Johnston, "Physiological and pathophysiological roles of excitatory amino acids during central nervous system development," Brain Research Reviews, vol. 15, no. 1, pp. 41-70, 1990.

[2] B. S. Meldrum, "Glutamate as a neurotransmitter in the brain: review of physiology and pathology," Journal of Nutrition, vol. 130, no. 4, pp. 1007S-1015S, 2000.

[3] M. J. Niciu, B. Kelmendi, and G. Sanacora, "Overview of glutamatergic neurotransmission in the nervous system," Pharmacology Biochemistry and Behavior, vol. 100, no. 4, pp. 656-664, 2012.
[4] V. Parpura and A. Verkhratsky, "Astroglial amino acid-based transmitter receptors," Amino Acids, vol. 44, no. 4, pp. 1151-1158, 2013.

[5] A. Efeyan, W. C. Comb, and D. M. Sabatini, "Nutrient-sensing mechanisms and pathways," Nature, vol. 517, no. 7534, pp. 302310, 2015.

[6] L. Galluzzi, F. Pietrocola, B. Levine, and G. Kroemer, "Metabolic control of autophagy," Cell, vol. 159, no. 6, pp. 1263-1276, 2014.

[7] Y. Kiriyama and H. Nochi, "The function of autophagy in neurodegenerative diseases," International Journal of Molecular Sciences, vol. 16, no. 11, pp. 26797-26812, 2015.

[8] V. Sica, L. Galluzzi, J. M. Bravo-San Pedro, V. Izzo, M. C. Maiuri, and G. Kroemer, "Organelle-specific initiation of autophagy," Molecular Cell, vol. 59, no. 4, pp. 522-539, 2015.

[9] A. Morikawa, K. Hamase, and K. Zaitsu, "Determination of Dalanine in the rat central nervous system and periphery using column-switching high-performance liquid chromatography," Analytical Biochemistry, vol. 312, no. 1, pp. 66-72, 2003.

[10] I. Rodríguez-Crespo, "D-Amino acids in the brain: pyridoxal phosphate-dependent amino acid racemases and the physiology of D-serine," FEBS Journal, vol. 275, no. 14, p. 3513, 2008.

[11] M. Yamanaka, Y. Miyoshi, H. Ohide, K. Hamase, and R. Konno, "D-Amino acids in the brain and mutant rodents lacking Damino-acid oxidase activity," Amino Acids, vol. 43, no. 5, pp. 1811-1821, 2012.

[12] J.-M. Billard, "Serine racemase as a prime target for age-related memory deficits," European Journal of Neuroscience, vol. 37, no. 12, pp. 1931-1938, 2013. 
[13] F. Errico, F. Napolitano, R. Nisticò, and A. Usiello, "New insights on the role of free D-aspartate in the mammalian brain," Amino Acids, vol. 43, no. 5, pp. 1861-1871, 2012.

[14] M. Martineau, V. Parpura, and J.-P. Mothet, "Cell-type specific mechanisms of D-serine uptake and release in the brain," Frontiers in Synaptic Neuroscience, vol. 6, article 12, 2014.

[15] S. Sacchi, "D-Serine metabolism: new insights into the modulation of d-amino acid oxidase activity," Biochemical Society Transactions, vol. 41, no. 6, pp. 1551-1556, 2013.

[16] A. Hashimoto, S. Kumashiro, T. Nishikawa et al., "Embryonic development and postnatal changes in free D-aspartate and Dserine in the human prefrontal cortex," Journal of Neurochemistry, vol. 61, no. 1, pp. 348-351, 1993.

[17] A. Hashimoto, T. Nishikawa, T. Hayashi et al., "The presence of free D-serine in rat brain," FEBS Letters, vol. 296, no. 1, pp. 3336, 1992.

[18] A. Hashimoto, T. Nishikawa, T. Oka, and K. Takahashi, "Endogenous $\mathrm{D}$-serine in rat brain: $\mathrm{N}$-methyl-D-aspartate receptorrelated distribution and aging," Journal of Neurochemistry, vol. 60, no. 2, pp. 783-786, 1993.

[19] A. Hashimoto, T. Oka, and T. Nishikawa, "Anatomical distribution and postnatal changes in endogenous free D-aspartate and D-serine in rat brain and periphery," European Journal of Neuroscience, vol. 7, no. 8, pp. 1657-1663, 1995.

[20] A. Hashimoto, T. Oka, and T. Nishikawa, "Extracellular concentration of endogenous free $\mathrm{D}$-serine in the rat brain as revealed by in vivo microdialysis," Neuroscience, vol. 66, no. 3, pp. 635643, 1995.

[21] J. De Miranda, A. Santoro, S. Engelender, and H. Wolosker, "Human serine racemase: moleular cloning, genomic organization and functional analysis," Gene, vol. 256, no. 1-2, pp. 183-188, 2000.

[22] H. Wolosker, S. Blackshaw, and S. H. Snyder, "Serine racemase: a glial enzyme synthesizing D-serine to regulate glutamateN-methyl-D-aspartate neurotransmission," Proceedings of the National Academy of Sciences of the United States of America, vol. 96, no. 23, pp. 13409-13414, 1999.

[23] H. Wolosker, K. N. Sheth, M. Takahashi et al., "Purification of serine racemase: biosynthesis of the neuromodulator D-serine," Proceedings of the National Academy of Sciences of the United States of America, vol. 96, no. 2, pp. 721-725, 1999.

[24] R. Inoue, K. Hashimoto, T. Harai, and H. Mori, "NMDA- and $\beta$-amyloid $_{1-42}$-induced neurotoxicity is attenuated in serine racemase knock-out mice," Journal of Neuroscience, vol. 28, no. 53, pp. 14486-14491, 2008.

[25] V. Labrie, R. Fukumura, A. Rastogi et al., "Serine racemase is associated with schizophrenia susceptibility in humans and in a mouse model," Human Molecular Genetics, vol. 18, no. 17, pp. 3227-3243, 2009.

[26] M. A. Benneyworth, Y. Li, A. C. Basu, V. Y. Bolshakov, and J. T. Coyle, "Cell selective conditional null mutations of serine racemase demonstrate a predominate localization in cortical glutamatergic neurons," Cellular and Molecular Neurobiology, vol. 32, no. 4, pp. 613-624, 2012.

[27] J. T. Ehmsen, T. M. Ma, H. Sason et al., "D-serine in glia and neurons derives from 3-phosphoglycerate dehydrogenase," Journal of Neuroscience, vol. 33, no. 30, pp. 12464-12469, 2013.

[28] E. Kartvelishvily, M. Shleper, L. Balan, E. Dumin, and H. Wolosker, "Neuron-derived D-serine release provides a novel means to activate N-methyl-D-aspartate receptors," Journal of Biological Chemistry, vol. 281, no. 20, pp. 14151-14162, 2006.
[29] K. Miya, R. Inoue, Y. Takata et al., "Serine racemase is predominantly localized in neurons in mouse brain," Journal of Comparative Neurology, vol. 510, no. 6, pp. 641-654, 2008.

[30] M. R. Van-Horn, M. Sild, and E. S. Ruthazer, "D-serine as a gliotransmitter and its roles in brain development and disease," Frontiers in Cellular Neuroscience, vol. 7, no. 39, 2013.

[31] H. Wolosker and I. Radzishevsky, "The serine shuttle between glia and neurons: implications for neurotransmission and neurodegeneration," Biochemical Society Transactions, vol. 41, no. 6, pp. 1546-1550, 2013.

[32] J. De Miranda, R. Panizzutti, V. N. Foltyn, and H. Wolosker, "Cofactors of serine racemase that physiologically stimulate the synthesis of the N-methyl-D-aspartate (NMDA) receptor coagonist D-serine," Proceedings of the National Academy of Sciences of the United States of America, vol. 99, no. 22, pp. 14542-14547, 2002.

[33] A. Neidle and D. S. Dunlop, "Allosteric regulation of mouse brain serine racemase," Neurochemical Research, vol. 27, no. 12, pp. 1719-1724, 2002.

[34] L. Balan, V. N. Foltyn, M. Zehl et al., "Feedback inactivation of D-serine synthesis by NMDA receptor-elicited translocation of serine racemase to the membrane," Proceedings of the National Academy of Sciences of the United States of America, vol. 106, no. 18, pp. 7589-7594, 2009.

[35] E. Dikopoltsev, V. N. Foltyn, M. Zehl et al., "FBXO22 protein is required for optimal synthesis of the N-methyl-D-aspartate (NMDA) receptor coagonist D-serine," The Journal of Biological Chemistry, vol. 289, no. 49, pp. 33904-33915, 2014.

[36] G. Kolodney, E. Dumin, H. Safory et al., "Nuclear compartmentalization of serine racemase regulates $\mathrm{d}$-serine production: implications for n-methyl-d-aspartate (NMDA) receptor activation," Journal of Biological Chemistry, vol. 290, no. 52, pp. 31037-31050, 2015.

[37] A. K. Mustafa, D. B. Van Rossum, R. L. Patterson et al., "Glutamatergic regulation of serine racemase via reversal of PIP2 inhibition," Proceedings of the National Academy of Sciences of the United States of America, vol. 106, no. 8, pp. 2921-2926, 2009.

[38] P. M. Kim, H. Aizawa, P. S. Kim et al., "Serine racemase: activation by glutamate neurotransmission via glutamate receptor interacting protein and mediation of neuronal migration," Proceedings of the National Academy of Sciences of the United States of America, vol. 102, no. 6, pp. 2105-2110, 2005.

[39] K. Fujii, K. Maeda, T. Hikida et al., "Serine racemase binds to PICK1: potential relevance to schizophrenia," Molecular Psychiatry, vol. 11, no. 2, pp. 150-157, 2006.

[40] Z. Zhuang, B. Yang, M. H. Theus et al., "EphrinBs regulate Dserine synthesis and release in astrocytes," Journal of Neuroscience, vol. 30, no. 47, pp. 16015-16024, 2010.

[41] F. Baumgart, J. M. Mancheño, and I. Rodríguez-Crespo, "Insights into the activation of brain serine racemase by the multi-PDZ domain glutamate receptor interacting protein, divalent cations and ATP," FEBS Journal, vol. 274, no. 17, pp. 4561-4571, 2007.

[42] Y. Li, N. Zhang, Y. Wang, Y. Shen, and Y. Wang, "Multiple faces of protein interacting with $\mathrm{C}$ kinase 1 (PICK1): structure, function, and diseases," Neurochemistry International, vol. 98, pp. 115-121, 2016.

[43] T. M. Ma, B. D. Paul, C. Fu et al., "Serine racemase regulated by binding to stargazin and PSD-95: potential N-methyl-D-aspartate- $\alpha$-amino-3-hydroxy-5-methyl-4-isoxazolepropionic acid (NMDA-AMPA) glutamate neurotransmission cross-talk," Journal of Biological Chemistry, vol. 289, no. 43, pp. 29631-29641, 2014. 
[44] V. N. Foltyn, I. Bendikov, J. De Miranda et al., "Serine racemase modulates intracellular D-serine levels through an $\alpha, \beta$-elimination activity," The Journal of Biological Chemistry, vol. 280, no. 3, pp. 1754-1763, 2005.

[45] M. J. Schell, R. O. Brady Jr., M. E. Molliver, and S. H. Snyder, "D-serine as a neuromodulator: regional and developmental localizations in rat brain glia resemble NMDA receptors," Journal of Neuroscience, vol. 17, no. 5, pp. 1604-1615, 1997.

[46] J.-P. Mothet, M. Le Bail, and J.-M. Billard, "Time and space profiling of NMDA receptor co-agonist functions," Journal of Neurochemistry, vol. 135, no. 2, pp. 210-225, 2015.

[47] A. Panatier, D. T. Theodosis, J.-P. Mothet et al., "Glia-derived Dserine controls NMDA receptor activity and synaptic memory," Cell, vol. 125, no. 4, pp. 775-784, 2006.

[48] T. Papouin, L. Ladépêche, J. Ruel et al., "Synaptic and extrasynaptic NMDA receptors are gated by different endogenous coagonists," Cell, vol. 150, no. 3, pp. 633-646, 2012.

[49] Y. Yang, W. Ge, Y. Chen et al., "Contribution of astrocytes to hippocampal long-term potentiation through release of D-serine," Proceedings of the National Academy of Sciences of the United States of America, vol. 100, no. 25, pp. 15194-15199, 2003.

[50] E. Karakas and H. Furukawa, "Crystal structure of a heterotetrameric NMDA receptor ion channel," Science, vol. 344, no. 6187, pp. 992-997, 2014.

[51] C.-H. Lee, W. Lü, J. C. Michel et al., "NMDA receptor structures reveal subunit arrangement and pore architecture," Nature, vol. 511, no. 7508, pp. 191-197, 2014.

[52] M. C. Regan, A. Romero-Hernandez, and H. Furukawa, "A structural biology perspective on NMDA receptor pharmacology and function," Current Opinion in Structural Biology, vol. 33, pp. 68-75, 2015.

[53] J.-P. Mothet, A. T. Parent, H. Wolosker et al., "D-serine is an endogenous ligand for the glycine site of the N-methyl-D-aspartate receptor," Proceedings of the National Academy of Sciences of the United States of America, vol. 97, no. 9, pp. 4926-4931, 2000.

[54] J. Sasabe, Y. Miyoshi, M. Suzuki et al., "D-Amino acid oxidase controls motoneuron degeneration through D-serine," Proceedings of the National Academy of Sciences of the United States of America, vol. 109, no. 2, pp. 627-632, 2012.

[55] G. Fisher, N. Lorenzo, H. Abe et al., "Free D- and L-amino acids in ventricular cerebrospinal fluid from Alzheimer and normal subjects," Amino Acids, vol. 15, no. 3, pp. 263-269, 1998.

[56] C. Madeira, M. V. Lourenco, C. Vargas-Lopes et al., "D-serine levels in Alzheimer's disease: implications for novel biomarker development," Translational Psychiatry, vol. 5, article no. e561, 2015.

[57] D. T. Balu and J. T. Coyle, “The NMDA receptor 'glycine modulatory site' in schizophrenia: D-serine, glycine, and beyond," Current Opinion in Pharmacology, vol. 20, pp. 109-115, 2015.

[58] V. Labrie, A. H. C. Wong, and J. C. Roder, "Contributions of the D-serine pathway to schizophrenia," Neuropharmacology, vol. 62, no. 3, pp. 1484-1503, 2012.

[59] G. Tsai, P. Yang, L.-C. Chung, N. Lange, and J. T. Coyle, "Dserine added to antipsychotics for the treatment of schizophrenia," Biological Psychiatry, vol. 44, no. 11, pp. 1081-1089, 1998.

[60] P. Paul and J. De Belleroche, "The role of D-amino acids in amyotrophic lateral sclerosis pathogenesis: a review," Amino Acids, vol. 43, no. 5, pp. 1823-1831, 2012.

[61] J. Sasabe, T. Chiba, M. Yamada et al., "D-Serine is a key determinant of glutamate toxicity in amyotrophic lateral sclerosis," EMBO Journal, vol. 26, no. 18, pp. 4149-4159, 2007.
[62] W. Kakegawa, Y. Miyoshi, K. Hamase et al., "D-Serine regulates cerebellar LTD and motor coordination through the $\delta 2$ glutamate receptor," Nature Neuroscience, vol. 14, no. 5, pp. 603-613, 2011.

[63] D. Yamazaki, J. Horiuchi, K. Ueno et al., "Glial dysfunction causes age-related memory impairment in Drosophila," Neuron, vol. 84, no. 4, pp. 753-763, 2014.

[64] K. Strisovsky, J. Jiráskova, A. Mikulová, L. Rulíšek, and J. Konvalinka, "Dual substrate and reaction specificity in mouse serine racemase: identification of high-affinity dicarboxylate substrate and inhibitors and analysis of the $\beta$-eliminase activity," Biochemistry, vol. 44, no. 39, pp. 13091-13100, 2005.

[65] A. Hashimoto and T. Oka, "Free D-aspartate and D-serine in the mammalian brain and periphery," Progress in Neurobiology, vol. 52, no. 4, pp. 325-353, 1997.

[66] S. Karakawa, K. Shimbo, N. Yamada et al., "Simultaneous analysis of D-alanine, D-aspartic acid, and D-serine using chiral high-performance liquid chromatography-tandem mass spectrometry and its application to the rat plasma and tissues," Journal of Pharmaceutical and Biomedical Analysis, vol. 115, pp. 123-129, 2015.

[67] H. Wolosker, A. D’Aniello, and S. H. Snyder, “D-aspartate disposition in neuronal and endocrine tissues: ontogeny, biosynthesis and release," Neuroscience, vol. 100, no. 1, pp. 183-189, 2000.

[68] A. Neidle and D. S. Dunlop, "Developmental changes in free Daspartic acid in the chicken embryo and in the neonatal rat," Life Sciences, vol. 46, no. 21, pp. 1517-1522, 1990.

[69] K. Hamase, H. Homma, Y. Takigawa, T. Fukushima, T. Santa, and K. Imai, "Regional distribution and postnatal changes of D-amino acids in rat brain," Biochimica et Biophysica ActaGeneral Subjects, vol. 1334, no. 2-3, pp. 214-222, 1997.

[70] Y. Kera, H. Aoyama, H. Matsumura, A. Hasegawa, H. Nagasaki, and R.-H. Yamada, "Presence of free D-glutamate and Daspartate in rat tissues," Biochimica et Biophysica Acta (BBA)General Subjects, vol. 1243, no. 2, pp. 282-286, 1995.

[71] D. S. Dunlop, A. Neidle, D. McHale, D. M. Dunlop, and A. Lajtha, "The presence of free D-aspartic acid in rodents and man," Biochemical and Biophysical Research Communications, vol. 141, no. 1, pp. 27-32, 1986.

[72] M. J. Schell, O. B. Cooper, and S. H. Snyder, "D-aspartate localizations imply neuronal and neuroendocrine roles," Proceedings of the National Academy of Sciences of the United States of America, vol. 94, no. 5, pp. 2013-2018, 1997.

[73] J.-A. Lee, H. Homma, K. Sakai et al., "Immunohistochemical localization of D-aspartate in the rat pineal gland," Biochemical and Biophysical Research Communications, vol. 231, no. 2, pp. 505-508, 1997.

[74] H. Han, Y. Miyoshi, K. Ueno et al., "Simultaneous determination of d-aspartic acid and d-glutamic acid in rat tissues and physiological fluids using a multi-loop two-dimensional HPLC procedure," Journal of Chromatography B: Analytical Technologies in the Biomedical and Life Sciences, vol. 879, no. 29, pp. 31963202, 2011.

[75] K. Sakai, H. Homma, J.-A. Lee et al., "D-aspartic acid localization during postnatal development of rat adrenal gland," Biochemical and Biophysical Research Communications, vol. 235, no. 2, pp. 433-436, 1997.

[76] K. Sakai, H. Homma, J.-A. Lee et al., "Localization of Daspartic acid in elongate spermatids in rat testis," Archives of Biochemistry and Biophysics, vol. 351, no. 1, pp. 96-105, 1998. 
[77] F. Errico, R. Nisticò, F. Napolitano et al., "Increased d-aspartate brain content rescues hippocampal age-related synaptic plasticity deterioration of mice," Neurobiology of Aging, vol. 32, no. 12, pp. 2229-2243, 2011.

[78] F. Errico, R. Nisticò, F. Napolitano et al., "Persistent increase of d-aspartate in d-aspartate oxidase mutant mice induces a precocious hippocampal age-dependent synaptic plasticity and spatial memory decay," Neurobiology of Aging, vol. 32, no. 11, pp. 2061-2074, 2011.

[79] F. Errico, R. Nisticò, G. Palma et al., "Increased levels of daspartate in the hippocampus enhance LTP but do not facilitate cognitive flexibility," Molecular and Cellular Neuroscience, vol. 37, no. 2, pp. 236-246, 2008.

[80] G. Molinaro, S. Pietracupa, L. Di Menna et al., "D-Aspartate activates mGlu receptors coupled to polyphosphoinositide hydrolysis in neonate rat brain slices," Neuroscience Letters, vol. 478, no. 3, pp. 128-130, 2010.

[81] P. M. Kim, X. Duan, A. S. Huang et al., "Aspartate racemase, generating neuronal D-aspartate, regulates adult neurogenesis," Proceedings of the National Academy of Sciences of the United States of America, vol. 107, no. 7, pp. 3175-3179, 2010.

[82] S. Matsuda, M. Katane, K. Maeda et al., "Biosynthesis of Daspartate in mammals: the rat and human homologs of mouse aspartate racemase are not responsible for the biosynthesis of D-aspartate," Amino Acids, vol. 47, no. 5, pp. 975-985, 2015.

[83] A. Tanaka-Hayashi, S. Hayashi, R. Inoue et al., "Is d-aspartate produced by glutamic-oxaloacetic transaminase-1 like 1 (Gotll1): a putative aspartate racemase?” Amino Acids, vol. 47, no. 1, pp. 79-86, 2015.

[84] M. Katane, T. Kawata, K. Nakayama et al., "Characterization of the enzymatic and structural properties of human D-aspartate oxidase and comparison with those of the rat and mouse enzymes," Biological and Pharmaceutical Bulletin, vol. 38, no. 2, pp. 298-305, 2015.

[85] M. Katane, Y. Saitoh, T. Hanai et al., “Thiolactomycin inhibits D-aspartate oxidase: a novel approach to probing the active site environment," Biochimie, vol. 92, no. 10, pp. 1371-1378, 2010.

[86] J. L. Still, M. V. Buell, W. Eugene Knox et al., "Studies on the cyclophorase system; D-aspartic oxidase," The Journal of Biological Chemistry, vol. 179, no. 2, pp. 831-837, 1949.

[87] K. Sakai, H. Homma, J.-A. Lee et al., "Emergence of D-aspartic acid in the differentiating neurons of the rat central nervous system," Brain Research, vol. 808, no. 1, pp. 65-71, 1998.

[88] D. Punzo, F. Errico, L. Cristino et al., "Age-related changes in D-aspartate oxidase promoter methylation control extracellular D-aspartate levels and prevent precocious cell death during brain aging," Journal of Neuroscience, vol. 36, no. 10, pp. 30643078, 2016.

[89] P. P. Van Veldhoven, C. Brees, and G. P. Mannaerts, "d-Aspartate oxidase, a peroxisomal enzyme in liver of rat and man," $B B A-$ General Subjects, vol. 1073, no. 1, pp. 203-208, 1991.

[90] F. Errico, J.-P. Mothet, and A. Usiello, "D-Aspartate: an endogenous NMDA receptor agonist enriched in the developing brain with potential involvement in schizophrenia," Journal of Pharmaceutical and Biomedical Analysis, vol. 116, pp. 7-17, 2015.

[91] F. Errico, M. T. Pirro, A. Affuso et al., "A physiological mechanism to regulate $\mathrm{D}$-aspartic acid and NMDA levels in mammals revealed by D-aspartate oxidase deficient mice," Gene, vol. 374, no. 1-2, pp. 50-57, 2006.

[92] H. Han, Y. Miyoshi, R. Koga, M. Mita, R. Konno, and K. Hamase, "Changes in d-aspartic acid and d-glutamic acid levels in the tissues and physiological fluids of mice with various d-aspartate oxidase activities," Journal of Pharmaceutical and Biomedical Analysis, vol. 116, pp. 47-52, 2014.

[93] A. S. Huang, A. Beigneux, Z. M. Weil et al., "D-aspartate regulates melanocortin formation and function: behavioral alterations in D-aspartate oxidase-deficient mice," The Journal of Neuroscience, vol. 26, no. 10, pp. 2814-2819, 2006.

[94] F. Errico, R. Nisticò, A. Di Giorgio et al., "Free D-aspartate regulates neuronal dendritic morphology, synaptic plasticity, gray matter volume and brain activity in mammals," Translational Psychiatry, vol. 4, article no. e417, 2014.

[95] F. Errico, V. D’Argenio, F. Sforazzini et al., "A role for Daspartate oxidase in schizophrenia and in schizophrenia-related symptoms induced by phencyclidine in mice," Translational Psychiatry, vol. 5, no. 2, article e512, 2015.

[96] F. Errico, F. Napolitano, M. Squillace et al., "Decreased levels of $\mathrm{d}$-aspartate and NMDA in the prefrontal cortex and striatum of patients with schizophrenia," Journal of Psychiatric Research, vol. 47, no. 10, pp. 1432-1437, 2013.

[97] S. Ishio, H. Yamada, M. Hayashi et al., "D-Aspartate modulates melatonin synthesis in rat pinealocytes," Neuroscience Letters, vol. 249, no. 2-3, pp. 143-146, 1998.

[98] Y. Takigawa, H. Homma, J.-A. Lee et al., "D-aspartate uptake into cultured rat pinealocytes and the concomitant effect on Laspartate levels and melatonin secretion," Biochemical and Biophysical Research Communications, vol. 248, no. 3, pp. 641-647, 1998.

[99] H. Wang, H. Wolosker, J. Pevsner, S. H. Snyder, and D. J. Selkoe, "Regulation of rat magnocellular neurosecretory system by Daspartate: evidence for biological role(s) of a naturally occurring free D-amino acid in mammals," Journal of Endocrinology, vol. 167, no. 2, pp. 247-252, 2000.

[100] A. D’Aniello, M. M. Di Fiore, G. H. Fisher et al., "Occurrence of $\mathrm{D}$-aspartic acid and N-methyl-D-aspartic acid in rat neuroendocrine tissues and their role in the modulation of luteinizing hormone and growth hormone release," The FASEB Journal, vol. 14, no. 5, pp. 699-714, 2000.

[101] G. D’Aniello, A. Tolino, A. D’Aniello, F. Errico, G. H. Fisher, and M. M. Di Fiore, "The role of D-aspartic acid and N-methyl-Daspartic acid in the regulation of prolactin release," Endocrinology, vol. 141, no. 10, pp. 3862-3870, 2000.

[102] E. Topo, A. Soricelli, A. D’Aniello, S. Ronsini, and G. D’Aniello, "The role and molecular mechanism of D-aspartic acid in the release and synthesis of $\mathrm{LH}$ and testosterone in humans and rats," Reproductive Biology and Endocrinology, vol. 7, article 120, 2009.

[103] A. D’Aniello, A. Di Cosmo, C. Di Cristo, L. Annunziato, L. Petrucelli, and G. Fisher, "Involvement of D-aspartic acid in the synthesis of testosterone in rat testes," Life Sciences, vol. 59, no. 2, pp. 97-104, 1996.

[104] A. Santillo, S. Falvo, P. Chieffi et al., "D-aspartate affects NMDA receptor-extracellular signal-regulated kinase pathway and upregulates androgen receptor expression in the rat testis," Theriogenology, vol. 81, no. 5, pp. 744-751, 2014.

[105] G. D’Aniello, S. Ronsini, T. Notari et al., "D-aspartate, a key element for the improvement of sperm quality," Advances in Sexual Medicine, vol. 02, no. 04, pp. 45-53, 2012.

[106] K. Hamase, A. Morikawa, S. Etoh, Y. Tojo, Y. Miyoshi, and K. Zaitsu, "Analysis of small amounts of D-amino acids and the study of their physiological functions in mammals," Analytical Sciences, vol. 25, no. 8, pp. 961-968, 2009.

[107] W. F. Visser, N. M. Verhoeven-Duif, R. Ophoff et al., "A sensitive and simple ultra-high-performance-liquid chromatographytandem mass spectrometry based method for the quantification 
of d-amino acids in body fluids," Journal of Chromatography A, vol. 1218, no. 40, pp. 7130-7136, 2011.

[108] H. Brückner and A. Schieber, "Ascertainment of D-amino acids in germ-free, gnotobiotic and normal laboratory rats," Biomedical Chromatography, vol. 15, no. 4, pp. 257-262, 2001.

[109] P. D. Hoeprich, "Alanine: cycloserine antagonism. Vi. demonstration of D-alanine in the serum of guinea pigs and mice," The Journal of biological chemistry, vol. 240, pp. 1654-1660, 1965.

[110] S. Karakawa, Y. Miyoshi, R. Konno et al., "Two-dimensional high-performance liquid chromatographic determination of day-night variation of $\mathrm{D}$-alanine in mammals and factors controlling the circadian changes," Analytical and Bioanalytical Chemistry, vol. 405, no. 25, pp. 8083-8091, 2013.

[111] G. E. Tsai, P. Yang, Y.-C. Chang, and M.-Y. Chong, "D-alanine added to antipsychotics for the treatment of schizophrenia," Biological Psychiatry, vol. 59, no. 3, pp. 230-234, 2006.

[112] K. R. Krijgsheld, E. J. Glazenburg, E. Scholtens, and G. J. Mulder, "The oxidation of L- and D-cysteine to inorganic sulfate and taurine in the rat," Biochimica et Biophysica Acta (BBA)General Subjects, vol. 677, no. 1, pp. 7-12, 1981.

[113] N. Shibuya, S. Koike, M. Tanaka et al., "A novel pathway for the production of hydrogen sulfide from D-cysteine in mammalian cells," Nature Communications, vol. 4, article no. 1366, 2013.

[114] N. Shibuya, M. Tanaka, M. Yoshida et al., "3-Mercaptopyruvate sulfurtransferase produces hydrogen sulfide and bound sulfane sulfur in the brain," Antioxidants and Redox Signaling, vol. 11, no. 4, pp. 703-714, 2009.

[115] Y. Kimura, Y. Toyofuku, S. Koike et al., "Identification of $\mathrm{H}_{2} \mathrm{~S}_{3}$ and $\mathrm{H}_{2} \mathrm{~S}$ produced by 3-mercaptopyruvate sulfurtransferase in the brain," Scientific Reports, vol. 5, Article ID 14774, 2015.

[116] K. Abe and H. Kimura, "The possible role of hydrogen sulfide as an endogenous neuromodulator," The Journal of Neuroscience, vol. 16, no. 3, pp. 1066-1071, 1996.

[117] A. Kumar, "NMDA receptor function during senescence: implication on cognitive performance," Frontiers in Neuroscience, vol. 9, article no. 473, 2015.

[118] Y. Kimura, Y. Mikami, K. Osumi, M. Tsugane, J.-I. Oka, and H. Kimura, "Polysulfides are possible $\mathrm{H}_{2} \mathrm{~S}$-derived signaling molecules in rat brain," FASEB Journal, vol. 27, no. 6, pp. 24512457, 2013.

[119] E. Shigetomi, O. Jackson-Weaver, R. T. Huckstepp, T. J. O’Dell, and B. S. Khakh, "TRPA1 channels are regulators of astrocyte basal calcium levels and long-term potentiation via constitutive d-serine release," The Journal of Neuroscience, vol. 33, no. 24, pp. 10143-10153, 2013.

[120] M. S. Vandiver, B. D. Paul, R. Xu et al., "Sulfhydration mediates neuroprotective actions of parkin," Nature Communications, vol. 4, article no. 1626, 2013.

[121] R. N. Carter and N. M. Morton, "Cysteine and hydrogen sulphide in the regulation of metabolism: insights from genetics and pharmacology," Journal of Pathology, vol. 238, no. 2, pp. 321332,2016

[122] K. Hamase, T. Inoue, A. Morikawa, R. Konno, and K. Zaitsu, "Determination of free D-proline and D-leucine in the brains of mutant mice lacking D-amino acid oxidase activity," Analytical Biochemistry, vol. 298, no. 2, pp. 253-258, 2001.

[123] K. Hamase, R. Konno, A. Morikawa, and K. Zaitsu, "Sensitive determination of $\mathrm{D}$-amino acids in mammals and the effect of D-amino-acid oxidase activity on their amounts," Biological and Pharmaceutical Bulletin, vol. 28, no. 9, pp. 1578-1584, 2005.

[124] A. Mangas, R. Coveñas, D. Bodet, M. Geffard, L. A. Aguilar, and J. Yajeya, "Immunocytochemical visualization of d-glutamate in the rat brain," Neuroscience, vol. 144, no. 2, pp. 654-664, 2007.
[125] É. Szökő, I. Vincze, and T. Tábi, “Chiral separations for d-amino acid analysis in biological samples," Journal of Pharmaceutical and Biomedical Analysis, vol. 130, pp. 100-109, 2016. 

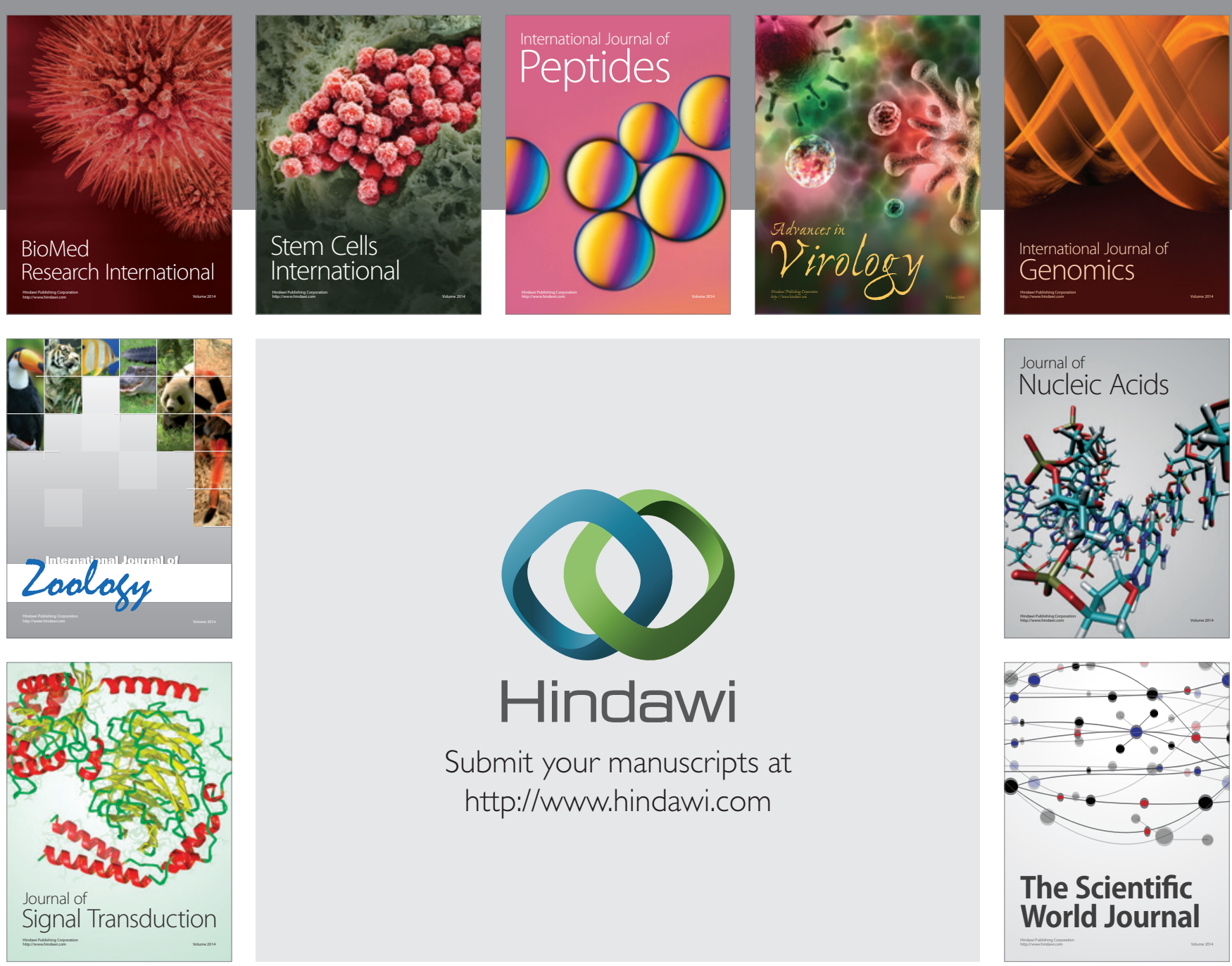

Submit your manuscripts at

http://www.hindawi.com
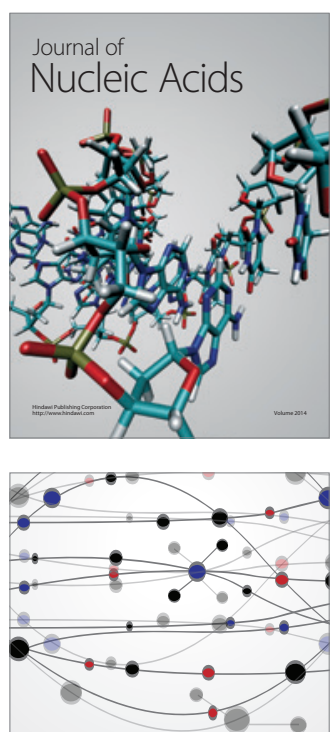

The Scientific World Journal
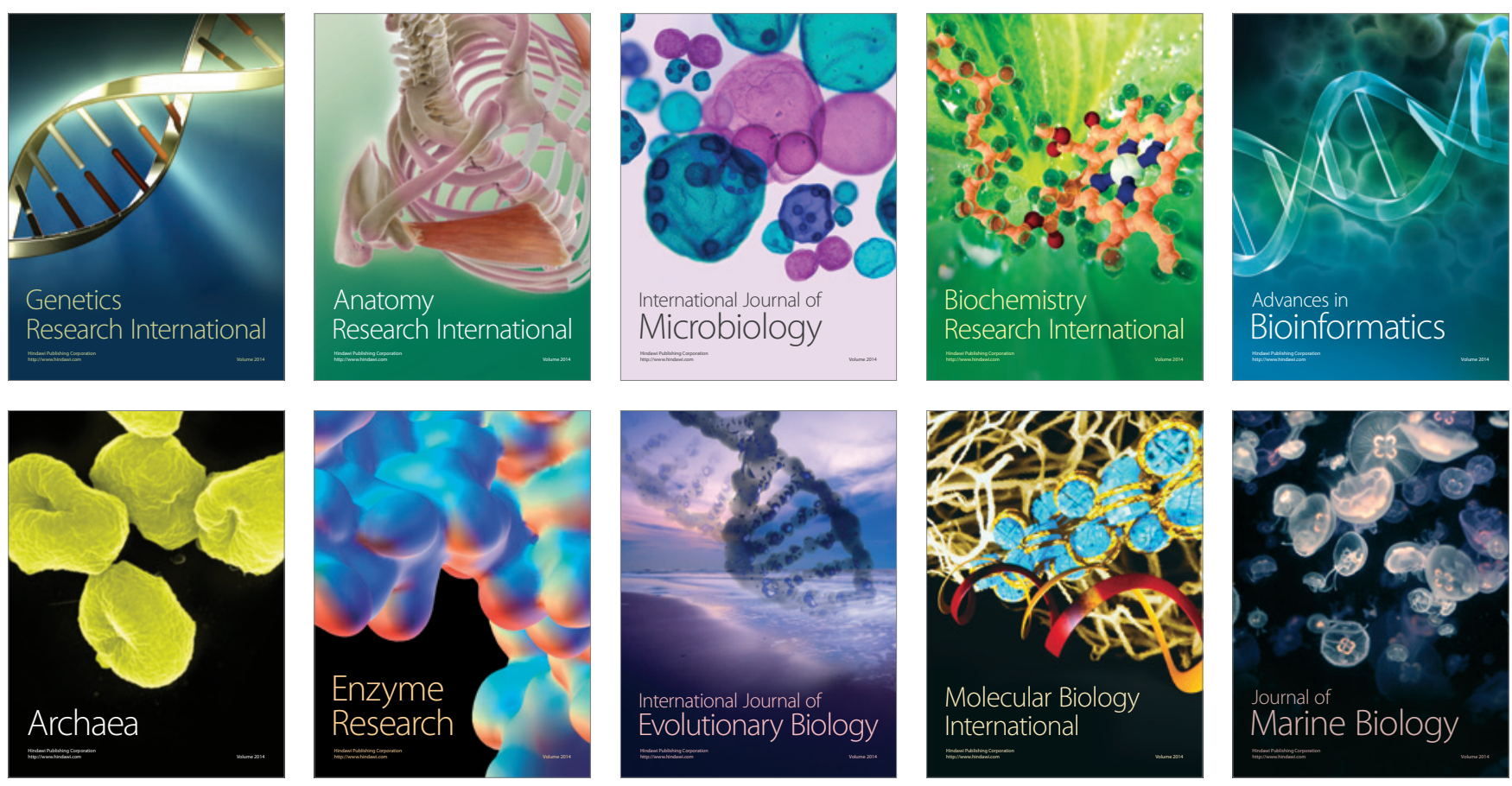